\title{
Actinostola callosa (Verrill, 1882) (Actinostolidae, Anthozoa), a medusivorous sea anemone and its mass occurrence in the Lurefjord, Norway
}

Received: 7 September 2002 / Revised: 11 July 2003 / Accepted: 11 July 2003 / Published online: 10 September 2003 (C) Springer-Verlag and AWI 2003

\begin{abstract}
The seafloor of two Norwegian fjords (Lurefjord and Sognefjord) was studied using a remotely operated vehicle (ROV). Two large sea anemone species, Actinostola callosa and Bolocera tuediae, are part of the benthic fauna of these fjords. The first species is the most abundant in the Lurefjord north of Bergen. A special linear model to calculate the distances between specimens was constructed using the Geographic Information System data from the ROV. A. callosa was found to be medusivorous. Its biomass and high abundance seem to be correlated with a mass occurrence of its important local prey, the coronate medusa Periphylla periphylla.
\end{abstract}

Keywords Cnidaria · Predation · Medusivorous . Periphylla periphylla $\cdot$ Norwegian fjords

\section{Introduction}

The fauna of several west Norwegian fjords have been studied during recent years with a focus on the Lurefjord which shows a mass occurrence of the deepwater scyphomedusa Periphylla periphylla (Fosså 1992; Jarms et al. 1999, 2002; Youngbluth and Båmstedt 2001). Recent studies of archibenthal are rare (e.g. Tyler and Zibrowius 1992). Our studies on the jellyfish P. periphylla in the Lurefjord have been based on a remotely operated vehicle (ROV). The ROV "Aglantha" is especially equipped for scientific studies, allowing video recording and environmental monitoring (see Båmstedt and Youngbluth 2000). The dives in the Lurefjord have revealed an abundance of large actinians, with Actinostola callosa as the dominant species. The use of the ROV

Communicated by H.-D. Franke

G. Jarms $(\bowtie) \cdot$ H. Tiemann

Zoologisches Institut und Zoologisches Museum,

Universität Hamburg,

Martin-Luther-King-Platz 3, 20146 Hamburg, Germany

e-mail: Gerhard.Jarms@zoologie.uni-hamburg.de

Tel.: +49-40-428382086

Fax: +49-40-428383937 provided in situ information on the appearance and behaviour of these organisms. We report here on the abundance and distribution of A. callosa in the Lurefjord, and on its trophic relationship to the jellyfish $P$. periphylla.

\section{Methods}

Biological material and video material were obtained using the ROV "Aglantha" in the deepest part (ca. $440 \mathrm{~m}$ ) of the Lurefjord $\left(05^{\circ} 10.00^{\prime} \mathrm{N}, 60^{\circ} 41.10^{\prime} \mathrm{E}\right)$ during two cruises with $\mathrm{R} / \mathrm{V}$ "Hăkon Mosby" in August 1999 and October 2000. For quantitative analysis of abundance and distribution patterns, the ROV was run along the bottom at a constant speed and defined distance to the seafloor. A simple geometric model was used to calculate the abundance. The analysis of the ROV transects was made using the Arc View 3.1a program from the computer company ESRI.

One specimen of Actinostola callosa was used for feeding experiments in the laboratory over a period of 7 days with live Periphylla medusae as prey. The experiment was performed in the dark at $6^{\circ} \mathrm{C}$. A conical net with a non-filtering cod-end collected the prey immediately before the experiment. After the experiment, the Actinostola specimen was preserved in $4 \%$ seawater-formaldehyde solution. It is deposited in the Zoological Museum Hamburg under no. ZMH C 11652

For morphological examinations, several individuals were collected from the soft bottom of the Lurefjord and preserved. Actinostola can be distinguished in the video material by its colour and habit. Both the short inner and the long peripheral tentacles of a collected specimen were cut off, and their characteristic supply of nematocysts was analysed by K. Riemann-Zürneck under a light microscope.

\section{Results}

External morphology

The analysis of the cnidome after Riemann-Zürneck (1978) revealed that the Lurefjord population belongs to Actinostola callosa (Verrill, 1882).

As there are no records of live specimens of A. callosa so far, we give a short description of this anemone as seen on the video. The column of A. callosa is yellowish-white and opaque. The pedal disk, if visible, is similar in 


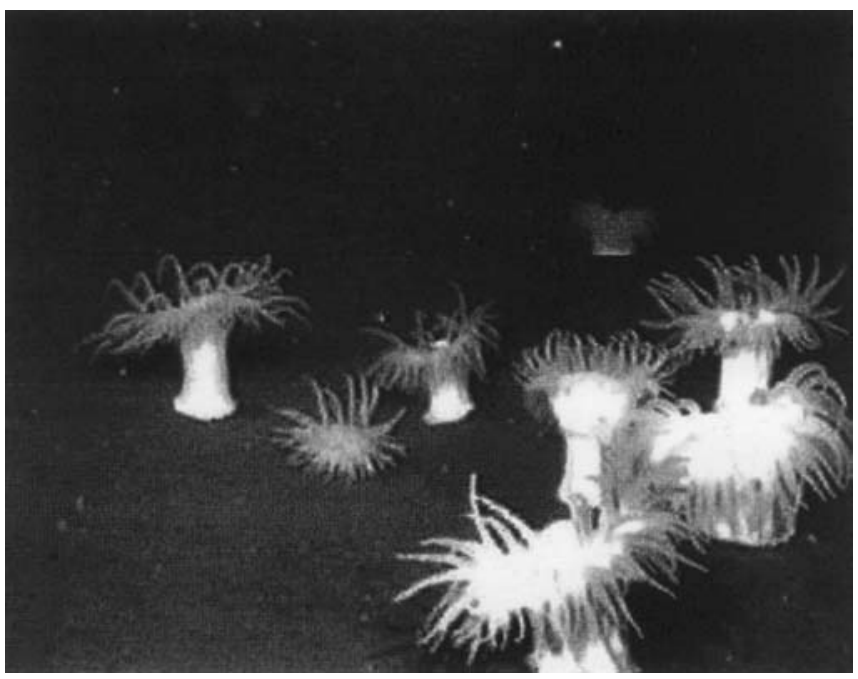

Fig. 1 A group of Actinostola callosa on the sea floor of the Lurefjord, western Norway; picture from a video taken by the ROV "Aglantha"

diameter to the column, and has the same colour. The marginal part of the column bearing the tentacular crown is widely extended and about twice the diameter of the column. Most specimens have their tentacles extended and held arched outwards. The fully expanded tentacles are as long as the column. From the video, we counted about 90-100 tentacles in large specimens, arranged in four circles. In the middle of the flat oral disc, the lips and upper part of the actinopharynx are bright yellow. We found this actinian species living on soft bottom (Fig. 1). The collected live specimen was $14 \mathrm{~cm}$ across and $18 \mathrm{~cm}$ high when relaxed in a bucket at $6^{\circ} \mathrm{C}$ half an hour after collection. This size was constant during the time of cultivation as long as the animal remained undisturbed. The measurements of the collected specimen gave us a scale to estimate the density of the big actinians. The preserved specimen is $10 \mathrm{~cm}$ high and has a weight of $427 \mathrm{~g}$.

\section{Abundance of Actinostola}

On all cruises (February, August, October, December), we found only large A. callosa on the seafloor. They were abundant on all transects analysed. Out of 24 transects, 18 provided sufficient information on travelled distance, and had a stable altitude and non-overlapping route to pass the criterion for quantification. From these data, we calculated that the individuals were an average distance of $4.9 \pm 3.2 \mathrm{~m}$ apart, corresponding to a density of $5.3 \pm 3.5$ individuals per $100 \mathrm{~m}^{2}$. However, clusters of up to seven specimens were common along the transects, with individuals usually $30-100 \mathrm{~cm}$ from each other (Fig. 1). Among such assemblages, single specimens were scattered at different distances from each other. Frequently, around the actinians but at a safe distance, there were several shrimps.

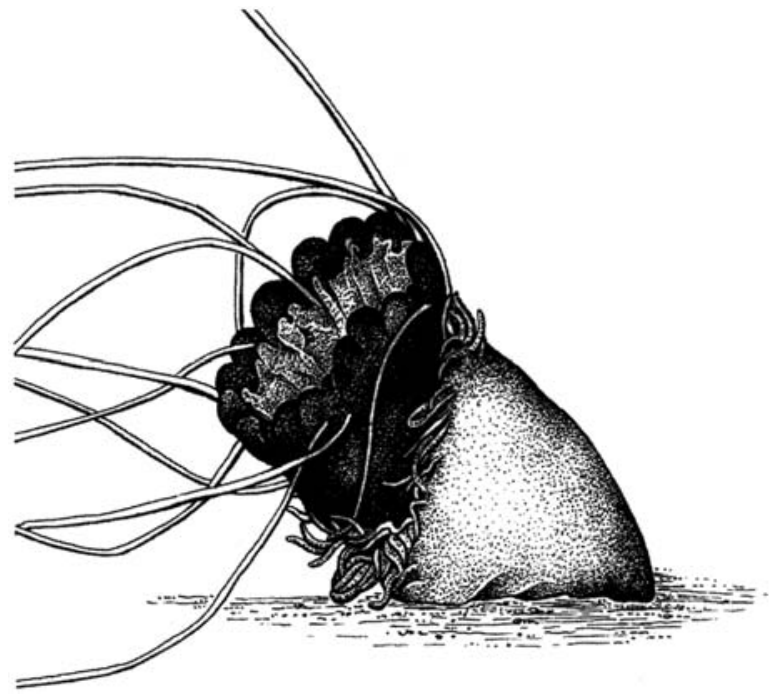

Fig. 2 A specimen of A. callosa devouring a big Periphylla periphylla on the sea floor of the Lurefjord, western Norway; drawing from a video image taken by the ROV "Aglantha"

Trophic relationships

During our ROV dives we observed several severely damaged medusae of Periphylla periphylla that appeared to have been partly devoured. One Actinostola had a medusa half inside its actinopharynx (Fig. 2). Several Actinostola were also observed with the typical Periphylla pigment around the mouth. The specimen mentioned above was observed for half an hour while gradually engulfing its prey. An in situ experiment was performed in order to test the ability of Actinostola to ingest big Periphylla. A medusa of about $15 \mathrm{~cm}$ in diameter was caught with the collecting device of the ROV and was placed near to the tentacles of the anemone. The tentacles of Actinostola stuck immediately to the medusa and pulled it to the mouth opening by shortening the tentacles. Although the diameter of the medusa was even larger than that of the anemone, Actinostola began to engulf the medusa while widening its mouth considerably. After $40 \mathrm{~min}$, the medusa was more than half ingested. The same experiment was repeated with the collected Actinostola (14 cm diameter) and a Periphylla of $6 \mathrm{~cm}$ diameter. The latter was totally ingested within 4 hours.

\section{Biomass relation between Actinostola and Periphylla}

As stated above, the abundance of Actinostola is $5.3 \pm 3.5$ specimens per $100 \mathrm{~m}^{2}$. The biomass of a wet specimen with squeezed-out gastrovascular system is about $500 \mathrm{~g}$. The total biomass of Actinostola thus amounts to at least $2,000 \mathrm{~g}$ per $100 \mathrm{~m}^{2}$. Youngbluth and Båmstedt (2001) reported an abundance of big Periphylla medusae (coronal diameter $6-16 \mathrm{~cm}$ ) of 2.5 specimens per $\mathrm{m}^{2}$ water column from 0-400 m depth (measured by net hauls). They estimated that about $10 \%$ of all medusae are this big 
size. An abundance of eight big medusae per $\mathrm{m}^{2}$ was counted by ROV observations.

The average biomass of a big medusa is $373 \mathrm{~g}$. The total biomass per $100 \mathrm{~m}^{2}$ thus amounts to about $100 \mathrm{~kg}$ (calculated from haul examination) or about $300 \mathrm{~kg}$ (from ROV counting).

\section{Discussion}

There are only a few video records of large anemones in deepwater habitats, for example from European waters by Howson and Davies (1991) and Tyler and Zibrowius (1992). Our ROV results indicate that there is a remarkably high density of Actinostola callosa on the bottom in the deepest part of the Lurefjord. Vader (1970) reported that A. callosa, besides Bolocera tuediae (Johnston) and Hormathia nodosa (Fabricius), is one of the characteristic anthozoan species of the epifauna of the muddy bottoms in the deeper basins of the Norwegian fjords. With a shrimp-trawl in the Korsfjord, he collected up to 140 specimens per haul. Unfortunately, towing times were not mentioned so that densities cannot be calculated. Size data for Actinostola are not available. But, within Vader's collection, $10-28 \%$ of the Bolocera specimens had a weight of more than $200 \mathrm{~g}$; the heaviest was $540 \mathrm{~g}$ and two specimens were $480 \mathrm{~g}$ each. Our specimen of Actinostola, at $427 \mathrm{~g}$, belongs to the same size class as the large Bolocera. This specimen was collected under video control out of a group of nearly equal-sized animals, and we found that more than $90 \%$ of the individuals were of that size. So we can conclude that, in the Lurefjord, the Actinostola population is not only very dense, but that individuals are also remarkably large. That corresponds to the findings of Riemann-Zürneck (1978): within the genus Actinostola, the species of the callosagroup are the biggest. Dredge samples of different actinian species from the south-west Atlantic, treated by Riemann-Zürneck and deposited in the Zoological Museum of Hamburg, mostly show only a single specimen, rarely two or a few more much smaller individuals. Thus, the abundance of Actinostola in the Lurefjord can be regarded as exceptionally high.

Only a small number of anemone species have been documented as medusivorous. Amongst those are Sargatiogeton laceratus predating upon the semaeostomean Aurelia aurita (Berryman 1984), and Entacmea medusivora described from the jellyfish lake in Palau feeding on the rhizostomean Mastigias papua (Fautin and Fitt 1991). Recently, Schwanitz (personal communication) saw Urticina felina swallowing Chrysaora hysoscella off Helgoland in the German Bight. All these records are from shallow waters. Whereas Entacmea seems to predate exclusively upon medusae, Sargatiogeton and Urticina are known to have a more diverse diet. Actinostola callosa is the first deepwater anemone now established as feeding on a coronate medusa. Further investigations of the food web of that particular Norwegian fjord will show whether Periphylla is the only prey of Actinostola.
The method used to study the softbottom benthos proved to be suitable and effective. The great variability of the data is due to the patchy distribution of the actinians and not to methodical deficiencies. In deepwater, about five specimens per $100 \mathrm{~m}^{2}$ seems to be a very high density for large animals such as these anemones. Due to the species' long lifespan, the Periphylla population does not show any significant seasonality in the Lurefjord, and all stages could be found throughout the year. We also found large specimens of Actinostola at different times of the year, which leads to the question of whether the high abundance of Actinostola may be related to the mass occurrence of Periphylla (Fosså 1992) in the same fjord. The biomass of Periphylla (calculated by Youngbluth and Båmstedt 2001) is about 100 times larger than the biomass of Actinostola (our calculation). From these findings, a predator prey relationship seems to be possible. Our in situ observations support this assumption, suggesting that the mass occurrence of Periphylla periphylla might be causing the high population density of $A$. callosa in the Lurefjord.

Acknowledgements This study was supported by the TMR program of the EU through contract no. ERBFMGECT950013. We are indebted to Karin Riemann-Zürneck who helped to determine the anemone species, and to Brigitte Hilbig for proof reading. We are grateful to Veit Hennig for his help with the computer analysis, and to Monika Hänel who made the drawing.

\section{References}

Båmstedt U, Youngbluth M (2000) Norwegian marine science goes deeper. Ocean Challenge 93:25-30

Berryman J (1984) Predation of Sargatiogeton laceratus upon Aurelia aurita in shallow water. J Mar Biol Assoc UK 64:725

Fautin DG, Fitt WK (1991) A jellyfish-eating sea anemone (Cnidaria, Actiniaria) from Palau: Entacmaea medusivora sp. nov. Hydrobiology 216/217:453-461

Fosså JH (1992) Mass occurrence of Periphylla periphylla (Scyphozoa, Coronatae) in a Norwegian fjord. Sarsia 77:237251

Howson CM, Davies LM (1991) Marine nature conservation review surveys of Scottish sea lochs. A towed video survey of Loch Fyne, vol 1. Nature Conservancy Council CSD Report 1189, February 1991 I-IV:1-41

Jarms G, Båmstedt U, Tiemann H, Martinussen MB, Fosså JH (1999) The holopelagic life cycle of the deep-sea medusa Periphylla periphylla (Scyphozoa, Coronatae). Sarsia 84:55-65

Jarms G, Tiemann H, Båmstedt U (2002) Development and biology of Periphylla periphylla (Peron \& Lesueur, 1809) (Scyphozoa, Coronatae) in a Norwegian fjord. Mar Biol 141:647-657

Riemann-Zürneck K (1978) Actinaria des Südwestatlantik IV. Actinostola crassicornis (Hertwig, 1882) mit einer Diskussion verwandter Arten. Veröff Inst Meeresforsch Bremerh 17:65-85

Tyler PA, Zibrowius H (1992) Submersible observations of the invertebrate fauna on the continental slope southwest of Ireland (NE Atlantic Ocean). Oceanol Acta 15:211-226

Vader W (1970) Amphipods associated with the sea anemone, Actinostola callosa, in western Norway. Sarsia 43:87-98

Youngbluth MJ, Båmstedt U (2001) Distribution, abundance, behavior and metabolism of Periphylla periphylla, a mesopelagic coronate medusa in a Norwegian fjord. Hydrobiologia 451:321-333 